Clinical practice guideline on atraumatic (pencil-point) vs conventional needles for lumbar puncture : Endorsement by the Scandinavian Society of Anaesthesiology and Intensive Care Medicine

Rehn, Marius

2019-04

Rehn , M , Chew , M S , Olkkola , K T , Sverrison, K O , Yli-Hankala , A \& Moller , M H 2019 , ' Clinical practice guideline on atraumatic (pencil-point) vs conventional needles for lumbar puncture : Endorsement by the Scandinavian Society of Anaesthesiology and Intensive Care Medicine ' , Acta Anaesthesiologica Scandinavica , vol. 63 , no. 4 , pp. 438-439 . https://doi.org/10.1111/aas.13312

http://hdl.handle.net/10138/313504

https://doi.org/10.1111/aas.13312

unspecified

publishedVersion

Downloaded from Helda, University of Helsinki institutional repository.

This is an electronic reprint of the original article.

This reprint may differ from the original in pagination and typographic detail.

Please cite the original version. 


\title{
Clinical practice guideline on atraumatic (pencil-point) vs conventional needles for lumbar puncture: Endorsement by the Scandinavian Society of Anaesthesiology and Intensive Care Medicine
}

\author{
Marius Rehn ${ }^{1,2,3}$ (D) | Michelle S. Chew ${ }^{4}$ | Klaus T. Olkkola ${ }^{5}$ Kristinn Ö. Sverrison ${ }^{6}$ | \\ Arvi Yli-Hankala $^{7,8}$ | Morten Hylander Møller ${ }^{9}$ (D)
}

${ }^{1}$ Pre-Hospital Division, Air Ambulance Department, Oslo University Hospital, Oslo, Norway

${ }^{2}$ The Norwegian Air Ambulance Foundation, Oslo, Norway

${ }^{3}$ Faculty of Health Sciences, University of Stavanger, Stavanger, Norway

${ }^{4}$ Department of Anaesthesia and Intensive Care, Medicine and Health, Linköping University, Linköping, Sweden

${ }^{5}$ Department of Anaesthesiology, Intensive Care and Pain Medicine, University of Helsinki and Helsinki University Hospital, Helsinki, Finland

${ }^{6}$ Department of Anaesthesia and Intensive Care Medicine, Landspitali University Hospital, Reykjavík, Iceland

${ }^{7}$ Department of Anaesthesia, Tampere University Hospital, Tampere, Finland

${ }^{8}$ Faculty of Medicine and Life Sciences, University of Tampere, Tampere, Finland

${ }^{9}$ Department of Intensive Care, Copenhagen University Hospital Rigshospitalet,

Copenhagen, Denmark

\section{Correspondence}

Marius Rehn, Pre-Hospital Division, Air Ambulance Department, Oslo University Hospital, Oslo, Norway.

Email: marius.rehn@norskluftambulanse.no

Funding information

Funding was provided solely from the SSAI and institutional and/or departmental sources.
The Scandinavian Society of Anaesthesiology and Intensive Care Medicine Clinical Practice Committee endorses the BMJ Rapid Recommendation clinical practice guideline on atraumatic (pencil-point) vs conventional needles for lumbar puncture. This includes the strong recommendation for the use of atraumatic needles for lumbar puncture in all patients regardless of age or indication.

\section{1 | BACKGROUND}

Anaesthesiologists and intensivists regularly perform lumbar punctures for therapeutic or diagnostic purposes. A common complication after lumbar puncture is sustained leakage of cerebrospinal fluid from a dural tear potentially causing debilitating postdural-puncture headache. ${ }^{1}$ It is recognized that needle design may 
influence cerebrospinal fluid leakage from the dural defect that is created during the puncture. ${ }^{2}$

In May 2018, Rochwerg et $a^{3}$ published a BMJ Rapid Recommendation clinical practice guideline on atraumatic (pencilpoint) vs conventional needles for lumbar puncture.

The Scandinavian Society of Anaesthesiology and Intensive Care Medicine (SSAI) Clinical Practice Committee (CPC) decided to appraise this guideline for possible endorsement to guide Scandinavian anaesthesiologists and intensivists in choice of atraumatic (pencilpoint) vs conventional needles for lumbar puncture.

\section{2 | METHODS}

The SSAI CPC assessed the guideline using the Appraisal of Guidelines for REsearch and Evaluation (AGREE) II tool, ${ }^{4}$ as per the outlined process for endorsement of non-SSAI guidelines (Figure S1).

\section{3 | RESULTS}

\section{1 | Quality appraisal (AGREE II)}

Five SSAI CPC members completed the appraisal. One member co-authored the guideline and was excluded from the evaluation (Figure S1).

The individual domain totals were: (a) scope and purpose $86 \%$; (b) stakeholder involvement 91\%; (c) rigor of development 87\%; (d) clarity of presentation $94 \%$; (e) applicability $78 \%$; (f) editorial independence 98\%; and (g) overall assessment 93\%.

The breakdown of the individual appraisers (de-identified) is available in the Supporting information.

\section{4 | DISCUSSION}

This clinical practice guideline on atraumatic (pencil-point) vs conventional needles for lumbar puncture achieved overall high ratings on all domains with acceptable agreement between the SSAI CPC appraisers.

\section{5 | CONCLUSION}

The SSAI CPC endorses the BMJ Rapid Recommendation clinical practice guideline on atraumatic (pencil-point) vs conventional needles for lumbar puncture ${ }^{3}$ including the strong recommendation for the use of atraumatic needles for lumbar puncture in all patients regardless of age or indication.

\section{ACKNOWLEDGEMENTS}

None.

\section{CONFLICT OF INTEREST}

No Clinical Practice Committee member had direct conflicts of interest. MHM was a co-author of the guideline assessed and did not participate in the AGREE II assessment, as per the SSAI endorsement process. No other authors had indirect conflicts of interest.

\section{ORCID}

Marius Rehn (iD https://orcid.org/0000-0001-9519-241X

Morten Hylander Møller (iD https://orcid.org/0000-0002-6378-9673

\section{REFERENCES}

1. Lavi R, Yarnitsky D, Rowe JM, Weissman A, Segal D, Avivi I. Standard vs atraumatic Whitacre needle for diagnostic lumbar puncture: a randomized trial. Neurology. 2006;67:1492-1494.

2. Nath S, Koziarz A, Badhiwala JH, et al. Atraumatic versus conventional lumbar puncture needles: a systematic review and meta-analysis. Lancet. 2018;391:1197-1204.

3. Rochwerg B, Almenawer SA, Siemieniuk R, et al. Atraumatic (pencil-point) versus conventional needles for lumbar puncture: a clinical practice guideline. BMJ. 2018;361:k1920.

4. Brouwers MC, Kho ME, Browman GP, et al. AGREE II: advancing guideline development, reporting and evaluation in health care. CMAJ. 2010;182:E839-E842.

\section{SUPPORTING INFORMATION}

Additional supporting information may be found online in the Supporting Information section at the end of the article.

How to cite this article: Rehn M, Chew MS, Olkkola KT, Sverrison KÖ, Yli-Hankala A, Møller MH. Clinical practice guideline on atraumatic (pencil-point) vs conventional needles for lumbar puncture: Endorsement by the Scandinavian Society of Anaesthesiology and Intensive Care Medicine. Acta Anaesthesiol Scand. 2019;63:438-439. https://doi.org/10.1111/ aas.13312 